\title{
The Journal of Plant Pathology for the International Year of Plant Health (IYPH) 2020, A Special Issue
}

Published online: 21 August 2020

(C) Società Italiana di Patologia Vegetale (S.I.Pa.V.) 2020

Plants are the foundation of life on earth. They produce the oxygen we breathe. They provide more than $80 \%$ of the food we eat. We use them to make clothes, shelter, medicines, and many other things that are essential to our lives. For nearly half of the earth's population, plants are a primary source of income. Almost every country trades plants and plant products to create wealth and support economic development. A threat to plant health is also a threat to the health and prosperity of people across the globe - especially the most vulnerable.

Plants are under constant attack from invasive pests. These pests can severely damage crops, forests, and other natural resources that people depend on. Every year, they cause billions of dollars of losses in crops and trade revenue, in addition to expensive eradication efforts. People, especially through international travel and trade, most often spread them. Despite declining resources for research in general, and for agricultural research in particular, Universities and research centers as well as international, regional and national plant health organizations continue in their efforts to protect plant.

The UN Food and Agriculture Organization and the International Plant Protection Convention Secretariat, based at FAO, welcomed the UN General Assembly's adoption today of a resolution proclaiming 2020 as the International Year of Plant Health (IYPH). This year is expected to increase awareness among the public and policy makers of the importance of healthy plants and the necessity to protect them in order to achieve the Sustainable Development Goals. Any effort to achieve the vision set out by the 2030 Agenda for Sustainable Development must acknowledge the critical importance of plant health. An International Year of Plant Health is essential to raise awareness, drive concrete action and ultimately contribute to a safer, more prosperous and peaceful world.

All over the world Institutions and plant pathologists are planning and running many, diverse outreach activities. Also the Italian Society of Plant Pathology, through this special issue of its Journal, wishes to contribute to the International Year of Plant Health.

\section{Maria Lodovica Gullino \\ Past President \\ Italian Society of Plant Pathology}

Publisher's note Springer Nature remains neutral with regard to jurisdictional claims in published maps and institutional affiliations. 